\title{
Subsidies for Intracity and Intercity Commuting
}

\author{
RAINALD BORCK \\ MATTHIAS WREDE
}

CESIFO WORKING PAPER NO. 2321

CATEGORY 1: PuBliC FinANCE

JUNE 2008
An electronic version of the paper may be downloaded
- from the SSRN website: Www.SSRN.com
- from the RePEc website: $\quad$ www.RePEc.org
- from the CESifo website: www.CESifo-group.org/wp




\title{
Subsidies for Intracity and Intercity Commuting
}

\begin{abstract}
This paper analyzes subsidies for intracity and intercity commuting in an urban economics framework with two cities and agglomeration externalities, where workers may commute within and between cities. First, commuting subsidies serve to internalize agglomeration externalities: Intracity commuting subsidies give incentives to move to the larger city and intercity commuting subsidies make residents of the periphery commute to the core. Second, if agglomeration rents are locally captured, commuting subsidies act as a welfare enhancing transfer from the core to the periphery.
\end{abstract}

JEL Code: R14, R48.

Keywords: commuting subsidies, agglomeration externalities, intercity and intracity commuting.

\author{
Rainald Borck \\ University of Munich \\ Faculty of Economics \\ Ludwigstrasse 28 \\ 80539 Munich \\ Germany \\ rainald.borck@lrz.uni-muenchen.de
}

\author{
Matthias Wrede \\ University of Marburg \\ Faculty of Business Administration and \\ Economics \\ Am Plan 2 \\ 35032 Marburg \\ Germany \\ wrede@wiwi.uni-marburg.de
}

May 21, 2008 


\section{Introduction}

We study the role of commuting subsidies to achieve an efficient spatial allocation in an urban model with agglomeration externalities and long-distance as well as short-distance commuting. The analysis is motivated by theoretical and practical concerns. On the policy side, we note that commuting subsidies are widespread. For instance, studies find that in the US less than one third of the total costs of public transit is covered by fares, while user fees account for only $60 \%$ of total expenditures on highways. ${ }^{1}$ An interesting observation comes from a recent reform in Germany: the tax code was recently changed by eliminating deductibility of commuting distances of less than $20 \mathrm{~km}$. For larger distances, deductibility remains. In general, the widespread subsidization of commuting provokes the question of why these subsidies are paid, and why subsidy rates should vary with distance.

One possible explanation rests on politics: for instance, Borck and Wrede [6, 7] show how subsidies redistribute between rich and poor city dwellers and between renters and landowners.

Another explanation would be to look for efficiency reasons. Here, the literature has been somewhat divided. Brueckner [8], for instance, shows that in a standard urban model, commutings subsidies are inefficient because they distort land use. However, given the absence of externalities, this is not surprising. Hence, arguments for commuting subsidies rest either on pre-existing distortions, for instance, a distortive income tax (see Wrede $[14,15])$ or on externalities. For example, in an efficiency wage model, Zenou [16] shows that commuting subsidies may be beneficial by reducing unemployment. Martin [11] shows that commuting subsidies can correct inefficiencies from spatial mismatch (the problem that minority workers live far from jobs and therefore have higher unemployment rates and lower welfare), but the welfare gains are generally small compared to first best policies (which would eliminate the reasons leading to mismatch, such as discrimination in the housing market).

Arnott [2] studies congestion tolling in a model with traffic congestion and agglomeration effects. ${ }^{2}$ His model differs from ours in that it considers only one city (which has no

\footnotetext{
${ }^{1}$ See Borck [4] for more discussion and references.

${ }^{2}$ See also Verhoef and Nijkamp [13] for a very similar approach. They study the internalization of conges-
} 
explicit spatial dimension, rather commuting occurs between "islands") and he focusses on the trade-off between the internalization of congestion and agglomeration externalities. In contrast to Arnott [2], we focus on the optimal allocation of workers and residences across cities.

On the theoretical side, our paper also contributes to the literature by analyzing longdistance commuting between cities as well as short-distance commuting within cities. ${ }^{3}$ This seems to be relevant since, given agglomeration effects, the decisions to commute to employment center 1 or to employment center 2 obviously have different allocative effects. Therefore, we explicitly introduce these two margins of choice in a model which combines an Alonso-Muth-Mills urban model with agglomeration effects à la Henderson [10]. Agglomeration effects generally imply that social and private returns to working in a city do not coincide, and we show that differentiated subsidies to long- and short-distance commuting may achieve first-best efficiency. That is, our analysis can be viewed as a possible normative justification of why commuting should be subsidized and why longdistance commuting between cities and short-distance commuting within cities should be treated differently. The basic reason for subsidizing commuting is that workers do not receive their full marginal social product. Therefore, commuting subsidies help to ensure that workers commute to that employment center which yields the highest social output. Beyond that, however, (short-distance) commuting subsidies also serve to make workers choose the right place of residence.

The paper proceeds as follows. The next section introduces the model. In Section 3, we study the social planner problem how to allocate the population between two cities, where the choice variables relate to the resident and working populations. In Section 4, we focus on the market equilibrium, which is achieved by individuals choosing their place of residence and workplace. Section 5 discusses the choice of policy instruments, and the last section concludes.

tion and agglomeration externalities through congestion tolling and wage subsidies in a single monocentric city.

${ }^{3}$ Borck et al. [5] also study long-distance commuting but do not model the spatial extension of cities and hence ignore commuting within cities. 


\section{The model}

We consider an economy with two cities, labeled 1 and 2. There is a total of $N$ mobile workers. Workers simultaneously choose their place of residence and their place of work. That is, by commuting costlessly from one city to the other, workers may separate job and residence.

Workers confer Marshallian urbanization externalities upon each other, that is, a worker is more productive the larger the number of other workers in the city, perhaps because of knowledge spillovers (see Duranton and Puga [9] for the microfoundations of agglomeration economies). This is captured in a simplistic way by assuming that the wage rate earned by a worker working in city $i, w_{i}$, is a function of the local labor force, $H_{i}$. ${ }^{4}$ Suppose that the production function of firm $j$ in city $i$ is $y_{j i}=E\left(H_{i}\right) F\left(h_{j i}, l_{j i}\right)$, where $h_{j i}$ is labor employed by firm $j, H_{i}$ aggregate labor in the city, and $l_{j i}$ is an immobile input employed by firm $j$ in city $i$. The immobile input could be either buildings or publicly provided infrastructure. Without loss of generality, we assume that city 1 is endowed with a stock of the immobile input at least as large as that in city 2: $L_{1} \geq L_{2}$, where $L_{i}$ is the aggregate amount of the immobile input in city $i . F\left(h_{j i}, \cdot\right)$ is a linearly homogeneous function with $F(0, \cdot)=0$, positive but decreasing marginal products for both factors. The function $E\left(H_{i}\right)$, with $E(0) \geq 0$ and $E^{\prime}\left(H_{i}\right)>0$, captures the positive agglomeration externality. When $F(\cdot)$ fulfills the Inada-condition, $\lim _{H_{i} \rightarrow 0} F_{H}\left(H_{i}, \cdot\right)=\infty$, the "internal" marginal product of labor goes to infinity if the number of workers goes to zero. Together with $E(\cdot)>0$, the Inada condition precludes full agglomeration of labor (see Michel et al. [12]).

Firms are assumed to maximize profits under perfect competition. Each firm takes aggregate labor in the city as given. Thus, even though there are increasing returns at the city level, each firm views itself as facing constant returns. Hence, workers are paid their marginal product, and the wage of a worker working in city $i$ is

$$
w_{i}=E\left(H_{i}\right) F_{H}\left(H_{i}, L_{i}\right),
$$

where $H_{i}$ is the local labor force and profits are zero.

\footnotetext{
${ }^{4}$ This approach follows among others Henderson [10], Abdel-Rahman and Anas [1] and Michel et al. [12].
} 
Each city is linear and extends from zero to $r_{i}, i=1,2$, where the boundary $r_{i}$ is endogenously determined by individuals' residence choices. All workers working in a city commute to the central business district (CBD) to work; all those working in the other city first commute to the CBD and then from there to the other city. A natural way to think of this assumption is workers commuting by train, where the train stations are located in the city centers. Hence, regardless of where a worker works, if she lives at $r \mathrm{~km}$ from the $\mathrm{CBD}$, she incurs commuting costs of $t w r$ where $w$ is the wage and $t>0$ the inverse of travel speed (commuting costs are in terms of time). A worker who commutes long distance additionally incurs a cost of $k w$, with $k>0$, to commute from CBD to CBD.

An individual living at $r \mathrm{~km}$ from the $\mathrm{CBD}$ where she works supplies $1-t r$ units of labor. If she lives $r \mathrm{~km}$ from CBD $i$ and commutes to CBD $j$, she supplies $1-k-t r$ units of labor. We will assume that $1-t N-k>0$. This implies that even if everyone were to live in, say, city 2, then if the outermost resident commutes to city 1 they would still supply a positive amount of labor there (i.e. commuting does not take the entire workday).

The number of inhabitants of city $i$ working in the same city is denoted by $N_{i}$, the number of commuters from 2 to 1 by $M_{21}$. Without loss of generality, the focus is on long-distance commuting from CBD 2 to CBD 1, i.e. $M_{21} \geq 0$. Note that transport costs, together with homogeneity of workers, exclude two-way commuting.

We assume a regional government that aims to maximize the joint welfare of citizens. Thus, competition among local governments for mobile workers is absent. ${ }^{5}$ The government may subsidize commuting at rate $s_{s}$ within cities and at rate $s_{l}$ across cities. Short distance commuters in city $i$ receive $s_{s} w_{i} t r$, long-distance commuters from 2 to 1 receive $s_{s} w_{1} t r+$ $s_{l} w_{1} k$. These subsidies may come in the form of subsidized public transport, tolls or other transport fees below total costs, or income tax deductions for commuting expenses. Subsidies are financed by a lump-sum tax $T$ on all citizens. In order to obtain reasonable

\footnotetext{
${ }^{5}$ Introducing such competition may obviously be an interesting extension of our model. However, we note that in many countries, while city governments have some discretion over transport policies, many instruments such as income tax policies or large infrastructure policies tend to be under the control of regional or even national governments. Hence, our assumption seems to be a reasonable approximation of reality. Also, competition of governments would introduce another distortion, but we want to focus here on one distortion only and how to deal with it.
} 
rent schedules, we assume throughout the analysis that short distance subsidies do not exceed costs. Hence, we assume $s_{s} \leq 1$.

All workers live on plots of land of fixed size which is normalized to unity. Land rent at distance $r$ will be denoted by $p(r)$. We assume that utility, $v$, equals consumption, $c$. Given that plot size is fixed, this assumption is innocuous.

We assume that economic rents, namely land rents and the income of the immobile, are equally distributed among all citizens living in the respective city. Aggregate land rent in city $i$ is denoted by $R_{i}$, and immobile input income in city $i$ is denoted by $Q_{i}$. Per capita rents in city 1 and 2 are

$$
I_{1}=\frac{R_{1}+Q_{1}}{N_{1}} \quad \text { and } \quad I_{2}=\frac{R_{2}+Q_{2}}{N-N_{1}}
$$

Since our assumption on the distribution of rents affects the results regarding the necessity of subsidies, in Section 5 we also consider economic rents which are distributed equally among all workers.

Suppose first that nobody commutes from the city under consideration to the other city. Then utility for a worker living in city $i$ is given by

$$
v_{i}=c_{i}=w_{i}\left[1-\left(1-s_{s}\right) t r\right]-p_{i}(r)+I_{i}-T,
$$

which is simply the wage net of commuting costs, minus housing rents, plus economic rents minus tax. Solving (3) for land rent as a function of commuting distance defines an individual's bid rent function:

$$
p_{i}(r)=w_{i}\left[1-\left(1-s_{s}\right) t r\right]+I_{i}-T-c_{i}
$$

As usual, we assume that competition for land implies that the highest bidder lives on any plot. Thus, which of two individuals lives closer to the CBD will depend on the slope of the bid rent function

$$
\frac{\partial p_{i}(r)}{\partial r}=-\left(1-s_{s}\right) w_{i} t
$$

In particular, since commuting is time consuming, individuals with higher wages live closer to the CBD. ${ }^{6}$

\footnotetext{
${ }^{6}$ Of course, this assumption depends on equal housing consumption for all individuals. Otherwise, the slope of the bid rent function is given by the ratio of the net wage to housing consumption.
} 
At the city border, land rent must equal the agricultural land rent, which is normalized zero. Since $r_{i}=N_{i}$, we can solve $p_{i}\left(N_{i}\right)=0$, from (4) to find an expression for utility:

$$
c_{i}=w_{i}\left[1-\left(1-s_{s}\right) t N_{i}\right]+I_{i}-T
$$

Substituting back into (4) and using the definition of aggregate land rent, $R_{i}=\int_{0}^{N_{i}} p_{i}(r) d r$, this can be further reduced to

$$
c_{i}=w_{i}\left[1-\left(1-s_{s}\right) t \frac{N_{i}}{2}\right]+\frac{Q_{i}}{N_{i}}-T .
$$

Using the same procedure, we find the utility of residents in city 2 when all commute to city 1 by substituting $M_{21}$ for $N_{i}$ and taking account of long-distance commuting costs:

$$
c_{21}=w_{1}\left[1-\left(1-s_{l}\right) k-\left(1-s_{s}\right) t \frac{M_{21}}{2}\right]+\frac{Q_{i}}{M_{21}}-T .
$$

Residents of city 2 will only commute to CBD 1 if their wage net of commuting costs is higher in city 1 than in city 2 , i.e. if

$$
w_{1}\left[1-\left(1-s_{l}\right) k-\left(1-s_{s}\right) t r\right]>w_{2}\left[1-\left(1-s_{s}\right) t r\right] .
$$

Provided that $w_{1}>w_{2}$ it can easily be shown that there is a critical distance $\tilde{r}$ such that all residents living at distance $r>\tilde{r}$ work in CBD 2 and all residents living at $r \leq \tilde{r}$ commute to CBD 1, where

$$
\tilde{r}=\frac{\left(1-\left(1-s_{l}\right) k\right) w_{1}-w_{2}}{\left(1-s_{s}\right) t\left(w_{1}-w_{2}\right)} .
$$

Note that if some individuals commute from city 2 to city 1 , the commuters will live closer to the CBD of city 2 if they have higher bid rents for locations close to the CBD. Hence, if the wage in city 1 is higher than the wage in city 2, long-distance commuters will tend to have steeper bid rents and will, therefore, prefer to live close to the CBD.

With long-distance commuting the land rent in city 2 is, therefore,

$$
p_{2}(r)=\left\{\begin{array}{ll}
w_{1}\left[1-\left(1-s_{l}\right) k-\left(1-s_{s}\right) t r\right]-c_{21}+I_{2}-T & \text { for } r<\tilde{r} \\
w_{2}\left[1-\left(1-s_{s}\right) t r\right]-c_{2}+I_{2}-T & \text { otherwise }
\end{array} .\right.
$$


Hence, aggregate land rent in city 2 is given by

$$
\begin{aligned}
R_{2}= & \int_{0}^{M_{21}} p_{2}(r) d r+\int_{M_{21}}^{N_{2}+M_{21}} p_{2}(r) d r \\
= & w_{1}\left[1-\left(1-s_{l}\right) k-\left(1-s_{s}\right) t \frac{M_{21}}{2}\right] M_{21} \\
& +w_{2}\left(N_{2}+M_{21}\right)\left[1-\left(1-s_{s}\right) t \frac{\left(N_{2}+M_{21}\right)}{2}\right]-w_{2} M_{21}\left[1-\left(1-s_{s}\right) t \frac{M_{21}}{2}\right] . \\
& -c_{2} N_{2}-c_{21} M_{21}+\left(I_{2}-T\right)\left(N_{2}+M_{21}\right)
\end{aligned}
$$

There is then a kink of the land-rent schedule at the distance $\tilde{r}=M_{21}$ where a city 2 resident is just indifferent between commuting to city 1 or working in city 2 . At this kink, we have

$$
w_{1}\left[1-\left(1-s_{l}\right) k-\left(1-s_{s}\right) t M_{21}\right]-c_{21}=w_{2}\left[1-\left(1-s_{s}\right) t M_{21}\right]-c_{2} .
$$

At the urban fringe in city $2, r_{2}=N-N_{1}$, utility is

$$
c_{2}=w_{2}\left[1-\left(1-s_{s}\right) t\left(N-N_{1}\right)\right]+I_{2}-T .
$$

Using the pattern of locations, we can give a general formula for the government budget constraint: ${ }^{7}$

$$
\begin{aligned}
T & =\frac{1}{N}\left\{s_{s} t\left[w_{1} \int_{0}^{N_{1}} r d r+w_{2} \int_{M_{21}}^{M_{21}+N_{2}} r d r+w_{1} \int_{0}^{M_{21}} r d r\right]+s_{l} w_{1} k \int_{0}^{M_{21}} r d r\right\} \\
& =\frac{1}{N}\left\{s_{s} t w_{1} \frac{N_{1}^{2}}{2}+s_{s} t w_{2}\left[\frac{\left(N_{2}+M_{21}\right)^{2}}{2}-\frac{M_{21}^{2}}{2}\right]+s_{s} t w_{1} \frac{M_{21}^{2}}{2}+s_{l} w_{1} k M_{21}\right\} .
\end{aligned}
$$

Residents of city 1 , workers of city 2 , and workers of city 1 living in city 2 receive subsidies. Labor supply can now be written as

$$
\begin{aligned}
H_{1} & =\int_{0}^{N_{1}}(1-t r) d r+\int_{0}^{M_{21}}(1-k-t r) d r \\
& =N_{1}\left[1-t \frac{N_{1}}{2}\right]+M_{21}\left[1-k-t \frac{M_{21}}{2}\right], \\
H_{2} & =\int_{M_{21}}^{M_{21}+N_{2}}(1-t r) d r=N_{2}\left[1-t \frac{N_{2}+2 M_{21}}{2}\right] .
\end{aligned}
$$

In city 1 , each resident and each commuter from city 2 supplies one unit of time minus commuting time. In city 2 , labor is only supplied by a fraction of residents. Here, we assume that subsidies increase income, but do not directly reduce travel time.

\footnotetext{
${ }^{7}$ Since our main concern here is with efficiency, we will assume that a regional government collects revenue from both cities and uses this to finance efficiency enhancing subsidies.
} 


\section{Optimum allocation of workers}

We now characterize the socially optimal allocation of workers across communities, both in terms of residences, and in terms of employment. Due to our assumptions, the welfare maximum simply maximizes total output: population is homogeneous, the lot size is fixed, leisure is not explicitly modeled, and non-time costs of commuting are neglected. Hence, denoting output in city $i$ by $G\left(H_{i}, L_{i}\right)$, a social planner who can choose residences and workplaces solves

$$
\begin{array}{ll}
\max _{N_{1}, N_{2}, M_{21}} & Y=G\left(H_{1}, L_{1}\right)+G\left(H_{2}, L_{2}\right) \\
& \text { s.t. } N_{1}+N_{2}+M_{21}=N, N_{2} \geq 0, M_{21} \geq 0,(14), \text { and (15). }
\end{array}
$$

Substituting for $H_{1}$ and $H_{2}$ from (14) and (15), the Lagrangian can be written

$$
\begin{aligned}
L & =G\left(N_{1}\left[1-t \frac{N_{1}}{2}\right]+M_{21}\left[1-k-t \frac{M_{21}}{2}\right], L_{1}\right) \\
& +G\left(N_{2}\left[1-t \frac{N_{2}+2 M_{21}}{2}\right], L_{2}\right)+\lambda\left(N-N_{1}-N_{2}-M_{21}\right)+\mu_{1} N_{2}+\mu_{2} M_{21},
\end{aligned}
$$

and the corresponding first order conditions are

$$
\begin{aligned}
G_{H}\left(H_{1}, L_{1}\right)\left(1-t N_{1}\right)-\lambda & =0, \\
G_{H}\left(H_{2}, L_{2}\right)\left(1-t\left(N_{2}+M_{21}\right)-\lambda+\mu_{1}\right. & =0, \\
G_{H}\left(H_{1}, L_{1}\right)\left(1-k-t M_{21}\right)-G_{H}\left(H_{2}, L_{2}\right) t N_{2}-\lambda+\mu_{2} & =0 .
\end{aligned}
$$

Due to the non-convexity of the optimization problem, local maxima may not be global maxima. However, some characteristics of optima can be obtained by analyzing the first order conditions.

Case 1: $N_{2}=M_{21}=0$. This would imply full agglomeration of population $\left(N_{1}=N\right)$. The complementary slackness conditions are $\mu_{1}, \mu_{2} \geq 0$. Examining (17)-(19) shows that this implies

$$
\begin{aligned}
G_{H}\left(0, L_{2}\right)-G_{H}\left(N(1-t N / 2), L_{1}\right)(1-t N) & \leq 0 \\
G_{H}\left(N(1-t N / 2), L_{1}\right)(t N-k) & \leq 0 .
\end{aligned}
$$

Since $G_{H}=E(H) F_{H}(H, L)+E^{\prime}(H) F(H, L)$, we have: 
Proposition 1 Full agglomeration of population, $N_{1}=N$, can be socially optimal if and only if $k \geq t N$ and either (i) $E(0)>0$ and the Inada condition does not hold $\left(\lim _{H_{i} \rightarrow 0} F_{H}\left(H_{i}, \cdot\right)\right.$ is finite) or (ii) $E(0)=0$.

Thus, full agglomeration of population cannot be optimal only if long-distance commuting is sufficiently cheap, in particular, if commuting from CBD to CBD costs less than commuting within a city would if all workers were to live there. Further, if the Inada conditions hold, full agglomeration of population cannot be optimal, since then the marginal product of shifting one worker from city 1 to city 2 must be positive.

Case 2: $N_{2}=0, M_{21}>0$. We now have $\mu_{1} \geq 0, \mu_{2}=0$. Combining (17)-(19) gives

$$
\begin{aligned}
G_{H}\left(0, L_{2}\right)\left(1-t\left(N-N_{1}\right)\right)-G_{H}\left(H_{1}, L_{1}\right)\left(1-k-t\left(N-N_{1}\right)\right) & \leq 0 \\
G_{H}\left(H_{1}, L_{1}\right)\left(t\left(2 N_{1}-N\right)-k\right) & =0 .
\end{aligned}
$$

Thus, we have the following result:

Proposition 2 Full agglomeration of employment, $N_{2}=0$, can be socially optimal only if (i) $E(0)>0$ and the Inada condition does not hold $\left(\lim _{H_{i} \rightarrow 0} F_{H}\left(H_{i}, \cdot\right)\right.$ is finite) or (ii) $E(0)=0$. Furthermore, if $E(0)>0$ and the Inada condition holds $\left(\lim _{H_{i} \rightarrow 0} F_{H}\left(H_{i}, \cdot\right)=\right.$ $\infty)$, the optimal allocation satisfies

$$
N_{1}^{*}=\frac{N}{2}+\frac{k}{2 t}
$$

Case 3: $N_{2}>0, M_{21}=0$. We now have $\mu_{1}=0, \mu_{2} \geq 0$. From (17)-(19) we find

$$
\begin{aligned}
G_{H}\left(H_{1}, L_{1}\right)(1-k)-G_{H}\left(H_{2}, L_{2}\right) & \leq 0 \\
G_{H}\left(H_{1}, L_{1}\right)\left(1-t N_{1}\right)-G_{H}\left(H_{2}, L_{2}\right)\left(1-t\left(N-N_{1}\right)\right) & =0 .
\end{aligned}
$$

This shows that long-distance commuting is probably inefficient if it is very time consuming and if the differences in the stocks of immobile inputs are not too large. If $L_{1}=L_{2}$, a symmetric allocation without long-distance commuting, i.e. $N_{1}=N_{2}=N / 2$, possibly maximizes output. Indeed, as can readily be seen from (21), this will be the case if the production function is concave, i.e., $G_{H H}<0$. If $L_{1}>L_{2}$, an asymmetric allocation with $N_{1}>N_{2}>0$ and $M_{21}=0$ may also be an optimum. 
Case 4: $N_{2}>0, M_{21}>0$. We now have $\mu_{1}, \mu_{2}>0$. Combining (17)-(19) gives

$$
\begin{aligned}
G_{H}\left(H_{1}, L_{1}\right)\left[1-k-t\left(N-N_{1}-N_{2}\right)\right] & =G_{H}\left(H_{2}, L_{2}\right)\left[1-t\left(N-N_{1}-N_{2}\right)\right] \\
G_{H}\left(H_{1}, L_{1}\right)\left(1-t N_{1}\right) & =G_{H}\left(H_{2}, L_{2}\right)\left[1-t\left(N-N_{1}\right)\right] .
\end{aligned}
$$

According to the second condition, the social marginal product of labor should be equalized for the outermost residents. The first condition requires that at distance $M_{21}$ in city 2 opting for long-distance commuting should neither increase nor decrease output.

These conditions imply

$$
N_{2}=\frac{\left[1-t\left(N-N_{1}\right)\right]\left[k+t\left(N-2 N_{1}\right)\right]}{\left(2 N_{1}-N\right) t^{2}} .
$$

Since we have assumed $1>k+t N$ and since the optimum with long-distance commuting requires $N_{1}>N / 2$ and $N_{2}>0$, we conclude that $N_{1}<N / 2+k /(2 t)$ holds.

An asymmetric interior allocation, where $N_{1}, N_{2}$, and $M_{21}$ are all greater than zero, may also be optimal. From closer inspection of the problem it becomes immediately clear that an asymmetric allocation with long-distance commuting is only optimal when agglomeration externalities are sufficiently strong and long-distance commuting costs $k$ are sufficiently low. Otherwise, a less asymmetric allocation without long-distance commuting maximizes output. Moreover, (22) directly implies $G_{H}\left(H_{1}, L_{1}\right)>G_{H}\left(H_{2}, L_{2}\right)$, i.e. that workers commute to the CBD with the higher social marginal product of labor. Since working hours in CBD 1 are more valuable than in CBD 2, efficiency requires that in city 2 longdistance commuters live closer to the CBD than short-distance commuters. Furthermore, as an implication of (22), $M_{21}+N_{2}<N / 2<N_{1}$. Long-distance commuting to CBD 1 is only optimal if already more than half the population lives in city 1. Moreover, a very large difference between input endowments, $L_{1} \gg L_{2}$ also makes this type of optimum more likely. Finally, as already been stated, $N_{2}>0$.

\section{Migration equilibria and subsidies}

We now study market equilibria, where individuals can freely migrate and commute, that is, they choose their place of residence and their place of work based on the utility obtained 
when living and working in city 1 versus living and working in city 2 or living in city 2 and working in 1.

Let us then look at the choice of residence and workplace. As is usual in the new economic geography literature, we assume a myopic adjustment process. That is, the change in population and in workforce is governed by the ad-hoc dynamics

$$
\begin{gathered}
\dot{N}_{1}=\left(c_{1}-c_{2}\right) N_{1}\left(N-N_{1}\right), \\
\dot{M}_{21}=\left(c_{21}-c_{2}\right) M_{21}\left(N-N_{1}\right),
\end{gathered}
$$

where the dot indicates derivatives with respect to time. Then, we find interior equilibria with $N_{1}<N, 0<M_{21}<N-N_{1}$ if

$$
c_{1}\left(N_{1}, M_{21}\right)=c_{2}\left(N_{1}, M_{21}\right)=c_{21}\left(N_{1}, M_{21}\right),
$$

where $c_{i}\left(N_{1}, M_{21}\right), i=1,2$ and $c_{21}\left(N_{1}, M_{21}\right)$ are given by (6) and (7) in combination with the government budget constraint, (13). By contrast, we get corner solutions with full agglomeration of population if $c_{1}(N, \cdot) \geq c_{2}(N, \cdot)$. Likewise, there would be no longdistance commuting if $c_{21}\left(N_{1}, 0\right) \leq c_{2}\left(N_{1}, 0\right)$ while all city 2 residents would commute to city 1 if $c_{21}\left(N_{1}, N-N_{1}\right) \geq c_{2}\left(N_{1}, N-N_{1}\right)^{8}$

Provided that $L_{1}=L_{2}$, the symmetric allocation $N_{1}=N_{2}=N / 2$ is obviously an equilibrium regardless of the size of subsidies, since utility is the same in both cities and due to equal wages no one can gain from long-distance commuting.

From (27), an equilibrium with long-distance commuting where $N_{1}, N_{2}, M_{21}>0$ is characterized by

$$
\begin{aligned}
w_{1}\left[1-\left(1-s_{l}\right) k-\left(1-s_{s}\right) t\left(N-N_{1}-N_{2}\right)\right] & =w_{2}\left[1-\left(1-s_{s}\right) t\left(N-N_{1}-N_{2}\right)\right], \\
w_{1}\left[1-\left(1-s_{s}\right) t N_{1}\right]+I_{1} & =w_{2}\left[1-\left(1-s_{s}\right) t\left(N-N_{1}\right)\right]+I_{2},
\end{aligned}
$$

where we have used $M_{21}=N-N_{1}-N_{2}$. The first condition ensures that at the kink of the land-rent schedule in city 2 , residents are indifferent between long-distance commuting and working in the city of residence. The second condition equalizes utility of the outermost residents in both cities.

\footnotetext{
${ }^{8}$ The last two conditions are obviously equivalent to $\tilde{r} \leq 0$ and $\tilde{r} \geq N-N_{1}$.
} 
Using the aggregate land rent formula (10), consumption at the urban fringe (12) and (27) yields

$$
R_{2}=\frac{\left(1-s_{s}\right) t}{2}\left\{w_{1} M_{21}^{2}+w_{2}\left[\left(M_{21}+N_{2}\right)^{2}-M_{21}^{2}\right]\right\}
$$

which is equal to net aggregate commuting costs within city 2 (see [3]).

In city 2, long-distance commuters only live closer to the CBD than short-distance commuters - as required by efficiency - if $w_{1}\left[1-\left(1-s_{l}\right) k\right]>w_{2}$ and $w_{1}>w_{2}$. The former condition implies that at the CBD 2 long-distance commuters are willing to pay more for land than CBD-2 workers, the second condition ensures that the bid-rent curve of the former group is steeper than that of the latter group.

By comparison of the first-order conditions of the social optimum and the market equilibrium conditions, i.e., on the one hand, (22) and (28), and, on the other hand, (23) and (29), it becomes clear that an interior migration equilibrium with $N_{1}, N_{2}, M_{21}>0$ would in general not be spatially efficient with zero commuting subsidies. The reason is simply that due to agglomeration externalities workers do not accrue the full marginal benefit from moving residence and/or workplace to the core: Wages are not equal to the marginal social product of labor and commuters from the periphery to the core do not participate in economic rents earned in the core. By subsidizing commuting, internalization becomes possible. While short-distance commuting subsidies reduce the costs of living in the larger city, i.e., the core, long-distance commuting subsidies enhance the benefits of commuting from the periphery to the core. Indeed, it can be shown that subsidies may lead to first-best efficiency. We can solve (22), (23), (28), and (29) implicitly for the firstbest subsidies $s_{s}^{*}$ and $s_{l}^{*}$ (the equations for $s_{l}^{*}$ and $s_{s}^{*}$ are somewhat cumbersome and are, therefore, omitted):

Proposition 3 If spatial efficiency requires $N_{1}, N_{2}, M_{21}>0$ and $E\left(H_{1}\right) F_{H}\left(H_{1}, L_{1}\right)>$ $E\left(H_{2}\right) F_{H}\left(H_{2}, L_{2}\right)$, the efficient allocation can be supported by a combination of shortdistance commuting subsidies and long-distance commuting subsidies, where in general, $s_{l}^{*} \neq s_{s}^{*}$.

Numerical example. We now present a numerical example which shows what the optimal allocation is, depending on the parameters of the model, and how this can be supported 

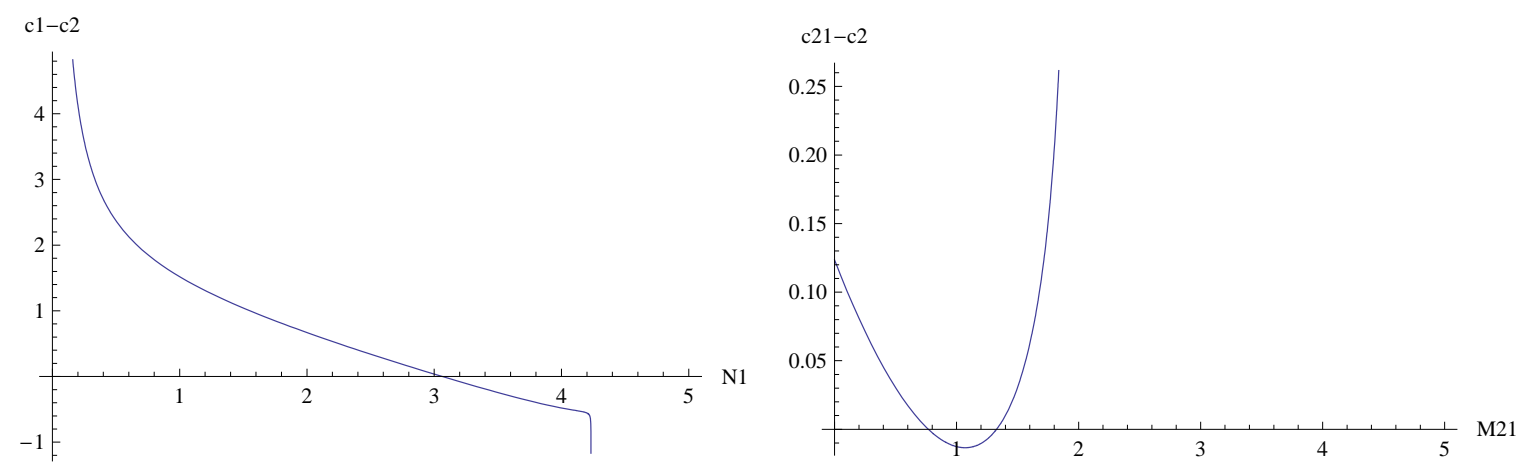

Figure 1: Stability of residence choice and commuting

by commuting subsidies. We assume a Cobb-Douglas "internal" production function

$$
F\left(H_{i}, L_{i}\right)=H_{i}^{\alpha} L_{i}^{1-\alpha}
$$

with $0<\alpha<1$, and an externality function

$$
E\left(H_{i}\right)=(H+c)^{\beta}
$$

where $c \geq 0$ and $0<\beta$. For parameters $N=5, k=0.1, t=0.08, c=0, \beta=0.3$, $\alpha=0.5, L_{1}=2$, and $L_{2}=1$, the optimum is $N_{1}=3.0628, N_{2}=1.1685$, and $M_{21}=0.7688$ (case 4). The core's wage exceeds the periphery's wage: $w_{1}=0.5550>0.4959=w_{2}$. A subsidy for long-distance commuting at rate $s_{l}=0.8009$ together with a tax on innercity commuting at rate $s_{s}=-12.2228$ restores the optimum as a migration equilibrium. While the long-distance commuting subsidy encourages commuting, the short-distance commuting tax discourages living in the core. This is necessary, since the aggregate land rent and the immobile input's income is much higher in the core than in the periphery: $I_{1}=1.50727>0.784398=I_{2}$. Local asymptotic stability of the equilibrium is also an issue. Calculating the trace and the determinant of the system defined by (25) and (26), stability can be verified. For this numerical example, it can be easily shown that the difference in consumption of resident workers in both cities, $c_{1}-c_{2}$, declines as $N_{1}$ increases. The same holds true around the equilibrium for the difference in consumption of commuters and local workers in city 2 , namely $c_{21}-c_{2}$, as $M_{21}$ increases (see figure 1 ).

If, everything else equal, we set $\beta=0.6$, the production function exhibits increasing aggregate returns to scale. Now, a corner solution where production is concentrated at 
the larger center 1 maximizes welfare (case 2), namely $N_{1}=3.125, N_{2}=0$, and $M_{21}=$ 1.875. Taxing inner-city commuting at $s_{s}=-11.1131$ and heavily subsidizing long-distance commuting at $s_{l}=8.64355$ supports this optimum.

Furthermore, if $k$ is very large, for example $k=0.8$, long distance commuting is inefficient. With increasing returns to scale $(\beta=0.6)$, the optimum is $N_{1}=N$ which does not require any subsidy (case 1$)$. With decreasing returns to scale $(\beta=0.3)$, the optimum is $N_{1}=3.4846, N_{2}=1.51542$ and $M_{21}=0$ (case 3). A short-distance commuting tax $s_{s}=-2$ supports this optimum.

In summary, the example shows that with increasing internal returns we find full agglomeration of production, while decreasing returns lead to an interior optimum. We also find that long-distance commuting is part of the optimum unless commuting costs are exceedingly large. Furthermore, the example shows that commuting subsidies may support the optimal allocation as a decentralized equilibrium, where in general, short-distance commuting is taxed and long-distance commuting subsidized.

\section{$5 \quad$ Further policy instruments}

There re a couple of features of the model which generally preclude the attainment of socially efficient equilibria: first, that workers' wages do not compensate them for the agglomeration externalities they generate, and second, that rents accrue only to city residents. Consider the first point: the fact that that workers are not paid their marginal social product. An obvious corrective policy would be to subsidize wages. Indeed, location specific wage subsidies are an alternative instrument which may be used to achieve the first best outcome. We do not elaborate on this point here, but note that wage subsidies would obviously have to be differentiated by residence, which in many countries may be deemed unconstitutional.

Another possibility would be to differentiate short-distance subsidies between cities. However, as we have seen in the previous section, this does not seem necessary to achieve efficiency.

Here, we focus instead on the second point, namely, the distribution of rents. So far, we have assumed that rents are distributed within each city to city residents. This seems 
to be standard in the literature (see e.g., Abdel-Rahman and Anas [1]). If, in contrast, rents are equally distributed across the entire metropolitan area, commuting subsidies no longer redistribute rents, but only correct the agglomeration externality with respect to long-distance commuting. Note that this assumes that the regional government can collect land rents (e.g. by taxing land rent) and immobile factor incomes and redistribute them equally to all residents of either city in the region.

Rents per capita are now $I=\left(R_{1}+R_{2}+Q_{1}+Q_{2}\right) / N$ and the equilibrium condition (29) becomes

$$
w_{1}\left[1-\left(1-s_{s}\right) t N_{1}\right]=w_{2}\left[1-\left(1-s_{s}\right) t\left(N-N_{1}\right)\right] .
$$

Thus, the major difference to the case of locally captured rents is that now rents play no role for the residence decision, since individuals earn the same share of rents regardless of their residence. Differing rents can, therefore, no longer influence the residence decision.

A comparison of, on the one hand, (22) and (28), and, on the other hand, (23) and (31), shows that the equilibrium conditions with zero subsidies $s_{s}=s_{l}=0$ would coincide with the first-order conditions of the central planner's problem if

$$
\frac{E^{\prime}\left(H_{1}^{*}\right) F\left(H_{1}^{*}, L_{1}\right)+E\left(H_{1}^{*}\right) F_{H}\left(H_{1}^{*}, L_{1}\right)}{E^{\prime}\left(H_{2}^{*}\right) F\left(H_{2}^{*}, L_{2}\right)+E\left(H_{2}^{*}\right) F_{H}\left(H_{2}^{*}, L_{2}\right)}=\frac{E\left(H_{1}^{*}\right) F_{H}\left(H_{1}^{*}, L_{1}\right)}{E\left(H_{2}^{*}\right) F_{H}\left(H_{2}^{*}, L_{2}\right)}
$$

where the left-hand side is the ratio of social marginal products of labor at the optimum, $G_{H}\left(H_{1}^{*}, L_{1}\right) / G_{H}\left(H_{2}^{*}, L_{2}\right)$, and the right-hand side is the ratio of internal marginal products of labor, i.e., the wage ratio. The same holds true for type 1 and type 2 optima and the respective equilibria.

A natural question is whether or not feasible production functions exist which always satisfy (32). Consider for example the Cobb-Douglas "internal" production function $F\left(H_{i}, L_{i}\right)=H_{i}^{\alpha} L_{i}^{1-\alpha}$, with $0<\alpha<1$. If $E\left(H_{i}\right)=H_{i}^{\beta}$, an asymmetric equilibrium without subsidy would satisfy the necessary conditions of spatial efficiency. However, this implies $E(0)=0$. Indeed, in order to fulfill (32) automatically, $E^{\prime}(H) F(H, L)$ has to be strictly proportional to $F_{H}(H, L) E(H)$. A necessary (but not sufficient) condition for this is $E(0)=0$. For instance, while $E(H)=H^{\beta}$ fulfills the condition, $\log (1+H)$ does not.

Whether or not commuting subsidies could be used to correct a market failure if it occurs, is not a priori clear. From (22), (28), (23), and (31) candidates for optimum subsidies $s_{s}^{*}$ and $s_{l}^{*}$ can again be calculated. The following proposition summarizes this: 
Proposition 4 If the production function is such that (32) holds, an efficient allocation can be sustained as a market equilibrium without subsidies. Otherwise, a combination of long-distance commuting subsidies and short-distance commuting subsidies can support the spatially efficient allocation, where, again, in general $s_{l}^{*} \neq s_{s}^{*}$.

While short-distance commuting subsidies have a direct impact on residence choices [see (31)], long-distance commuting subsidies are targeted at the commuting decision. If shortdistance commuting were not subsidized, i.e. if $s_{s}^{*}=0, E^{\prime}\left(H_{1}^{*}\right) F\left(H_{1}^{*}, L_{1}\right)\left(1-N_{1}^{*} t\right)-$ $E^{\prime}\left(H_{2}^{*}\right) F\left(H_{2}^{*}, L_{2}\right)\left[1-\left(N-N_{1}^{*}\right) t\right]=0$ would hold and, therefore, long-distance-commuting subsidies should be zero, too. Thus, either all commuters or no one is to be subsidized.

Numerical example In order to further analyze subsidies without local rent capture, we exploit the numerical example from the previous section. We focus on interior social optima. Clearly, if all parameters are the same, subsidies are superfluous with an equal rent distribution, since with $c=0, E^{\prime}(H) F(H, L)$ is strictly proportional to $F_{H}(H, L) E(H)$. With $c=0.2$, positive subsidies are necessary to achieve an efficient allocation of labor in a free migration equilibrium. The optimum is $N_{1}=3.0639, N_{2}=1.1443$, and $M_{21}=0.7917$. Still, the core's workers earn more than the periphery's workers: $w_{1}=0.5640>0.52557=$ $w_{2}$. The optimum subsidy rates are $s_{s}=0.3234$ and $s_{l}=0.3473$. Again, long-distance subsidies exceed short-distance subsidies.

In contrast to the previous section, subsidies don't have to offset local rent differences. Hence, to compensate for large commuting distances within the city, residents in the larger city also receive a positive (short-distance) subsidy.

\section{Concluding remarks}

This paper has analyzed subsidies for intracity and intercity commuting when agglomeration externalities are present. In order to analyze commuting within cities and between cities, the monocentric city framework was extended to a two-city model where workers choose where to live and where to work. In contrast to Abdel-Rahman and Anas [1] and many others, we have explicitly allowed for partial agglomeration of employment instead 
of full agglomeration. We have shown that commuting subsidies can help internalize externalities: Intracity commuting subsidies give incentives to move to the larger city and intercity commuting subsidies make residents of the periphery commute to the core. Commuting subsidies act as a welfare enhancing transfer from the core to the periphery. Note also that our analysis gives a rationale for differing treatment of short- and long-distance commuting, a policy that can be observed in some countries. One reason for this treatment may be that this way, government can redistribute rents from those working in the core to those working in the periphery.

There are several directions for further research. First, we have assumed that subsidies reduce monetary commuting costs but do not directly affect the time costs of commuting. It seems to be worthwhile to analyze the provision of traffic infrastructure which would directly reduce travel time and thus increase labor supply. Balancing speed improvement and infrastructure costs, the government would have a further incentive to subsidize commuting. Second, we have not considered locally financed commuting subsidies and have, therefore, excluded subsidy competition from our analysis. However, this choice seems natural if one wants - as we did - to focus on efficiency. Subsidy competition would bring about a further source of inefficiency, which is however, related to the organization of jurisdictions and not to the existence of correct instruments.

\section{References}

[1] H.M. Abdel-Rahman, A. Anas, Theories of systems of cities, In: J. V. Henderson and J. F. Thisse (ed.), Handbook of Regional and Urban Economics (2004), 2293-2339.

[2] R.J. Arnott, Congestion tolling with agglomeration externalities, Journal of Urban Economics 62 (2007), 187-203.

[3] R.J. Arnott, J.E. Stiglitz, Aggregate land rents and aggregate transport costs, Economic Journal 91 (1981), 331-347.

[4] R. Borck, The political economy of urban transit, forthcoming in OECD (ed.), Round Table on Privatisation and Regulation of Urban Transit, OECD, Paris (2007). 
[5] R.Borck, M. Pflüger, M. Wrede, A simple theory of industry location and residence choice, IZA discussion paper 2862 (2007).

[6] R. Borck, M. Wrede, Political economy of commuting subsidies, Journal of Urban Economics 57 (2005), 478-499.

[7] R. Borck, M. Wrede, Commuting subsidies with two transport modes, Journal of Urban Economics, forthcoming.

[8] J.K. Brueckner, Transport subsidies, system choice, and urban sprawl, Regional Science and Urban Economics 35 (2005), 715-733.

[9] G. Duranton, D. Puga, Micro-foundations of urban agglomeration economies, in: J. V. Henderson and J. F. Thisse (ed.), Handbook of Regional and Urban Economics, volume 4 (2004), 2063-2117.

[10] J.V. Henderson, The sizes and types of cities, American Economic Review 64 (1974), 640-656.

[11] R.W. Martin, Spatial mismatch and costly suburban commutes: Can commuting subsidies help?, Urban Studies 38 (2001), 1305-1318.

[12] P. Michel, A. Perrot, J.-F. Thisse, Interregional equilibrium with heterogeneous labor, Journal of Population Economics 9 (1996), 95-113.

[13] E.T. Verhoef, P. Nijkamp, Externalities in the urban economy, Tinbergen Institute discussion paper 2003-078/3 (2003).

[14] M. Wrede, Tax deductibility of commuting expenses and leisure: On the tax treatment of time-saving expenditure, FinanzArchiv 57 (2000), 216-224.

[15] M. Wrede, Should commuting expenses be tax deductible? A welfare analysis, Journal of Urban Economics 49 (2001), 80-99.

[16] Y. Zenou, Urban unemployment, agglomeration and transportation policies, Journal of Public Economics 77 (2000), 97-133. 


\section{CESifo Working Paper Series}

for full list see www.cesifo-group.org/wp

(address: Poschingerstr. 5, 81679 Munich, Germany, office@cesifo.de)

2261 J. Atsu Amegashie and Marco Runkel, The Paradoxes of Revenge in Conflicts, March 2008

2262 Hans Jarle Kind, Marko Koethenbuerger and Guttorm Schjelderup, Efficiency Enhancing Taxation in Two-sided Markets, March 2008

2263 M. Hashem Pesaran, Til Schuermann and L. Vanessa Smith, Forecasting Economic and Financial Variables with Global VARs, March 2008

2264 Volker Grossmann, Entrepreneurial Innovation and Sustained Long-run Growth without Weak or Strong Scale Effects, March 2008

2265 Robert S. Chirinko and Huntley Schaller, The Irreversibility Premium, March 2008

2266 Andrea Galeotti and José Luis Moraga-González, Platform Intermediation in a Market for Differentiated Products, April 2008

2267 Torben M. Andersen and Michael Svarer, The Role of Workfare in Striking a Balance between Incentives and Insurance in the Labour Market, April 2008

2268 Harald Badinger, Cyclical Fiscal Policy, Output Volatility, and Economic Growth, April 2008

2269 Thomas Aronsson and Erkki Koskela, Outsourcing and Optimal Nonlinear Taxation: A Note, April 2008

2270 Gary E. Bolton, Claudia Loebbecke and Axel Ockenfels, How Social Reputation Networks Interact with Competition in Anonymous Online Trading: An Experimental Study, April 2008

2271 Nikolaus Wolf, Scylla and Charybdis. Explaining Europe’s Exit from Gold, January 1928 - December 1936, April 2008

2272 Michael Funke and Marc Gronwald, The Undisclosed Renminbi Basket: Are the Markets Telling us something about where the Renminbi - US Dollar Exchange Rate is Going?, April 2008

2273 Thor Olav Thoresen and Annette Alstadsæter, Shifts in Organizational Form under a Dual Income Tax System, April 2008

2274 Helge Berger and Volker Nitsch, Too many Cooks? Committees in Monetary Policy, April 2008

2275 Yin-Wong Cheung and Eiji Fujii, Deviations from the Law of One Price in Japan, April 2008 
2276 Michael S. Michael, Sajal Lahiri and Panos Hatzipanayotou, Integrated Reforms of Indirect Taxes in the Presence of Pollution, April 2008

2277 Bas Jacobs, Is Prescott Right? Welfare State Policies and the Incentives to Work, Learn and Retire, April 2008

2278 Burkhard Heer and Alfred Maußner, Value Function Iteration as a Solution Method for the Ramsey Model, April 2008

2279 Jarko Fidrmuc and Christa Hainz, Integrating with their Feet: Cross-Border Lending at the German-Austrian Border, April 2008

2280 Kristof Dascher and Alexander Haupt, The Political Economy of Regional Integration Projects at Borders where Rich and Poor Meet: The Role of Cross-Border Shopping and Community Sorting, April 2008

2281 Katrin Assenmacher-Wesche and M. Hashem Pesaran, A VECX* Model of the Swiss Economy, April 2008

2282 Christophe Rault, Robert Sova and Ana Maria Sova, Modeling International Trade Flows between CEEC and OECD Countries, April 2008

2283 Timo Boppart, Josef Falkinger, Volker Grossmann, Ulrich Woitek and Gabriela Wüthrich, Qualifying Religion: The Role of Plural Identities for Educational Production, April 2008

2284 Armin Falk, David Huffman and W. Bentley MacLeod, Institutions and Contract Enforcement, April 2008

2285 Axel Dreher and Stefan Voigt, Does Membership in International Organizations Increase Governments' Credibility? Testing the Effects of Delegating Powers, April 2008

2286 Xavier Freixas and Bruno M. Parigi, Lender of Last Resort and Bank Closure Policy, April 2008

2287 Regina Dionisius, Samuel Muehlemann, Harald Pfeifer, Günter Walden, Felix Wenzelmann and Stefan C. Wolter, Cost and Benefit of Apprenticeship Training - A Comparison of Germany and Switzerland, April 2008

2288 Francesco Daveri and Cecilia Jona-Lasinio, Off-Shoring and Productivity Growth in the Italian Manufacturing Industries, April 2008

2289 Mikael Priks, Do Surveillance Cameras Affect Unruly Behavior? A Close Look at Grandstands, April 2008

2290 Marianna Belloc and Daniela Federici, A Two-Country NATREX Model for the Euro/Dollar, April 2008

2291 Nicolas Treich, The Value of a Statistical Life under Ambiguity Aversion, April 2008 
2292 J. Atsu Amegashie, Socially-Tolerable Discrimination, April 2008

2293 M. Hashem Pesaran and Andreas Pick, Forecasting Random Walks Under Drift Instability, April 2008

2294 Steven Brakman, Gus Garita, Harry Garretsen and Charles van Marrewijk, Unlocking the Value of Cross-Border Mergers and Acquisitions, May 2008

2295 Eric O’N. Fisher and Kathryn G. Marshall, The Structure of the American Economy, May 2008

2296 Claudia M. Buch and Martin Schlotter, Regional Origins of Employment Volatility: Evidence from German States, May 2008

2297 Helmuth Cremer, Philippe De Donder, Dario Maldonado and Pierre Pestieau, Taxing Sin Goods and Subsidizing Health Care, May 2008

2298 Reinhilde Veugelers and Frederick van der Ploeg, Reforming European Universities: Scope for an Evidence-Based Process, May 2008

2299 Jon H. Fiva and Lars J. Kirkebøen, Does the Housing Market React to New Information on School Quality?, May 2008

2300 Tina Klautke and Alfons J. Weichenrieder, Interest Income Tax Evasion, the EU Savings Directive, and Capital Market Effects, May 2008

2301 Harald Badinger and Peter Egger, GM Estimation of Higher Order Spatial Autoregressive Processes in Panel Data Error Component Models, May 2008

2302 Jan K. Brueckner, Slot-Based Approaches to Airport Congestion Management, May 2008

2303 Sören Blomquist, Vidar Christiansen and Luca Micheletto, Public Provision of Private Goods and Nondistortionary Marginal Tax Rates, May 2008

2304 Dan Anderberg and Alessandro Balestrino, The Political Economy of Post-Compulsory Education Policy with Endogenous Credit Constraints, May 2008

2305 Tomer Blumkin, Yoram Margalioth and Efraim Sadka, The Role of Stigma in the Design of Welfare Programs, May 2008

2306 Vesa Kanniainen and Paolo M. Panteghini, Tax Neutrality: Illusion or Reality? The Case of Entrepreneurship, May 2008

2307 Thomas Dohmen, Armin Falk, David Huffman and Uwe Sunde, The Intergenerational Transmission of Risk and Trust Attitudes, May 2008

2308 Guglielmo Maria Caporale and Mario Cerrato, Using Chebyshev Polynomials to Approximate Partial Differential Equations, May 2008 
2309 Peter Egger and Doina Maria Radulescu, Labour Taxation and Foreign Direct Investment, May 2008

2310 Laurent Linnemer, Dissipative Advertising Signals Quality even without Repeat Purchases, May 2008

2311 Jordi Jofre-Monseny and Albert Solé-Ollé, Which Communities should be afraid of Mobility? The Effects of Agglomeration Economies on the Sensitivity of Firm Location to Local Taxes, May 2008

2312 Andreas Haufler and Ferdinand Mittermaier, Unionisation Triggers Tax Incentives to Attract Foreign Direct Investment, May 2008

2313 Ronel Elul and Piero Gottardi, Bankruptcy: Is it enough to Forgive or must we also Forget?, May 2008

2314 Andreas Irmen and Johanna Kuehnel, Productive Government Expenditure and Economic Growth, May 2008

2315 Beate Henschel, Carsten Pohl and Marcel Thum, Demographic Change and Regional Labour Markets: The Case of Eastern Germany, May 2008

2316 Gabriel Felbermayr, Wido Geis and Wilhelm Kohler, Restrictive Immigration Policy in Germany: Pains and Gains Foregone?, May 2008

2317 Michael Hofmann, Gerhard Kempkes and Helmut Seitz, Demographic Change and Public Sector Budgets in a Federal System, May 2008

2318 Paul De Grauwe, Macroeconomic Modeling when Agents are Imperfectly Informed, June 2008

2319 Johann K. Brunner and Susanne Pech, Optimum Taxation of Inheritances, June 2008

2320 Thomas Eichner and Marco Runkel, Corporate Income Taxation of Multinationals in a General Equilibrium Model, June 2008

2321 Rainald Borck and Matthias Wrede, Subsidies for Intracity and Intercity Commuting, June 2008 